\title{
Estudo de Formulações e das Variáveis de Fabricação de um Suporte de Solda Cerâmico
}

\author{
(Study of Formulations and the Manufacturing Variables of a Ceramic Weld Backing)
}

\author{
Luciana Lezira Pereira de Almeida ${ }^{1}$, Luiz Cláudio Soares Tatagiba ${ }^{1}$, Carlos Maurício Vieira ${ }^{1}$, José Ramalho², Ronaldo Pinheiro da \\ Rocha Paranhos ${ }^{1}$ \\ ${ }^{1}$ LAMAV-CCT-UENF. Campos dos Goytacazes - R J - CEP:28013-602 - Brasil. paranhos@uenf.br \\ ${ }^{2}$ INFOSOLDA. R. Nair Correia Buarque, 39 - São Paulo - SP - CEP 05324-040 - Brasil
}

\begin{abstract}
Resumo
Este trabalho apresenta uma metodologia para a produção em laboratório de um suporte cerâmico para a execução de soldas unilaterais em aço. Formulações foram preparadas usando a cordierita, a bauxita e a magnesita como minerais refratários. A bentonita e o silicato de sódio neutro foram usados como aditivos à massa cerâmica. O processo de fabricação envolveu a mistura das matérias primas, a compactação por pressão, a secagem e sinterização dos corpos de prova. Os suportes de solda foram caracterizados por difração de raios-X, microscopia ótica da superfície, ensaios de absorção de água e de tensão de ruptura a flexão. Também foram submetidos à soldagem do passe de raiz pelo processo MIG-MAG. Os resultados mostram que a rota de fabricação cerâmica convencional é adequada à fabricação do suporte de solda cerâmico. Entre as formulações testadas, a cordierita apresentou melhor integridade tanto durante sua fabricação como durante a operação de soldagem, tendo produzido cordões de solda com bom acabamento e isento de descontinuidades. As variáveis de fabricação do suporte foram avaliadas, como a pressão de compactação, a temperatura de sinterização e a adição de água à massa cerâmica.
\end{abstract}

Palavras-Chaves: Suporte Cerâmico; Soldagem unilateral; Cordierita.

\begin{abstract}
This work presents a methodology for the in lab manufacturing of a ceramic backing for the one-side steel welds. Formulations were prepared using cordierite, bauxite and magnesite as refractory minerals. Bentonite and sodium silicate were used as addictives for the ceramic blend. The manufacturing process included dry mixture, compressing, drying and sintering of the specimens. The weld supports were characterized by X-ray diffraction, optical microscopy of the surface, water absorption and flexile tension. Also they were submitted to the welding of the root pass with the MIG-MAG process. The results show that the conventional ceramic manufacturing route is adequate for the production of the ceramic weld backing. Among the tested formulations, cordierite showed better integrity both during its manufacturing and during the welding operation, producing well shaped weld beads, free from discontinuities. The manufacturing variables were evaluated, such as the compacting pressure, sintering temperature and the amount of water added to the ceramic mass.
\end{abstract}

Key-words: Ceramic backing; one-sided welding; cordierite.

\section{Introdução}

A soldagem unilateral, como o próprio nome sugere, é uma técnica em que os cordões de solda são depositados somente por um lado da peça. Existem vários tipos de soldagem unilateral, que podem ser utilizadas com ajuda de suportes ou com juntas adequadas para a realização da soldagem [1].

Este trabalho dedica atenção ao suporte cerâmico, que tem a capacidade de tolerar a elevada temperatura da poça de solda quando no estado líquido, evita a formação de gases

(Recebido em 19/09/2009; Texto Final em 30/11/2009). durante a soldagem e proporciona um acabamento adequado do cordão de solda, isento de defeitos [2]. O suporte cerâmico é de fácil e rápida aplicação, sendo normalmente fixado à peça por meio de uma fita de alumínio adesiva na parte interna da junta a ser soldada. Pelas características apresentadas acima, o suporte cerâmico é considerado como uma efetiva solução para o aumento da produtividade da soldagem [1,2], obtendo um adequado acabamento e integridade do passe de raiz e, conseqüentemente, da junta soldada [3].

Em função das características intrínsecas dos materiais cerâmicos, como baixa densidade, baixa condutividade térmica, alta resistência à corrosão e à abrasão, capacidade de suportar altas temperaturas sem se deformar, a utilização desses materiais tem crescido significativamente em uma infinidade de aplicações [4]. A cerâmica refratária é uma categoria importante dos materiais cerâmicos. As propriedades destes materiais 
incluem que em elevadas temperaturas não se fundem e nem se decompõem, a capacidade de continuar não-reativo e inerte quando expostos em lugares severos e também a habilidade de proporcionar isolamento térmico [5].

Tendo em vista que na soldagem unilateral ocorre uma diversidade de situações de fabricação, como posição de soldagem, tipo de junta, tipo de chanfro, alinhamento/ desalinhamento da junta, juntas dissimilares, peças de formato reto ou curvado e processo de soldagem aplicável, é exigido que o suporte cerâmico se adapte às situações e, por conseguinte, possua diversas formas e dimensões [6].

O objetivo deste trabalho é produzir em laboratório o suporte cerâmico, determinando as matérias primas e possíveis formulações. Serão avaliadas as variáveis de fabricação do suporte, como a temperatura de sinterização e pressão de compactação e a adição de água à massa cerâmica. Ainda, propõe-se caracterizar as composições do suporte cerâmico após a queima, determinando suas propriedades físicas e mecânicas. Também foi avaliada a deposição do passe de raiz na soldagem unilateral usando-se o processo de soldagem MIG-MAG.

\section{MATERIAIS E MÉTODOS}

Duas classes de matérias-primas foram previamente identificadas, que são os óxidos refratários e aditivos que auxiliam a aglomeração da massa cerâmica.

Como refratários foram usados: a cordierita (43- $45 \%$ $\mathrm{Al}_{2} \mathrm{O}_{3}, 42-45 \% \mathrm{SiO}_{2}, 0,8-1,5 \% \mathrm{TiO}_{2}, 1,2-1,7 \% \mathrm{Fe}_{2} \mathrm{O}_{3}, 5,6-6,2 \%$ $\mathrm{MgO})$; a bauxita $\left(83,4 \% \mathrm{Al}_{2} \mathrm{O}_{3}, 7,14 \% \mathrm{SiO}_{2}, 1 \% \mathrm{TiO}_{2}, 7,07 \%\right.$ $\mathrm{Fe}_{2} \mathrm{O}_{3}$ e $\left.0,02 \% \mathrm{P}\right)$ e a magnesita $(96 \% \mathrm{MgO}, 0,60 \% \mathrm{CaO}, 2,60 \%$ $\mathrm{Fe}_{2} \mathrm{O}_{3}, 0,60 \% \mathrm{Al}_{2} \mathrm{O}_{3}$ e $1,60 \% \mathrm{SiO}_{2}$ ). Os aditivos utilizados foram: o silicato de sódio neutro $\left(30 \% \mathrm{SiO}_{2} ; 9,0 \% \mathrm{Na}_{2} \mathrm{O}\right.$ e $\left.61 \% \mathrm{H}_{2} \mathrm{O}\right)$ e a bentonita $\left(54 \% \mathrm{SiO}_{2}, 33 \% \mathrm{Al}_{2} \mathrm{O} 3,4 \% \mathrm{Na}_{2} \mathrm{O}\right.$ e $\left.10 \% \mathrm{H}_{2} \mathrm{O}\right)$. Ainda, água foi utilizada como uma variável do processo, pois é útil para a umidade da massa cerâmica a ser compactada.
Na primeira parte deste trabalho, as formulações utilizadas para a fabricação do suporte cerâmico são mostradas na tabela 1 . A preparação foi realizada de acordo com a seguinte sequiência de produção em escala de laboratório: a) pesagem das matérias primas; b) mistura seca; c) mistura úmida, com a adição água e silicato de sódio (quando usado) à mistura seca, de forma a produzir a massa cerâmica; d) peneiramento da mistura úmida, com uma peneira de \#40 mesh: e) compactação em prensa manual: a mistura foi prensada em um molde com dimensões de $115 \mathrm{~mm}$ de comprimento e $25 \mathrm{~mm}$ de largura, força de 7 ton por 1 min. A figura 1 apresenta a seção transversal do suporte cerâmico produzido onde pode ser observado uma pequena concavidade na região central, que tem a função de adequar o formato do cordão de solda quando no estado líquido na parte inferior da chapa; f) secagem: após a compactação, os corpos de prova foram submetidos a um processo de secagem em estufa com temperatura de $120{ }^{\circ} \mathrm{C}$ por $24 \mathrm{~h}$; g) sinterização: a temperatura e o tempo de sinterização foram considerados como variáveis do processo. $\mathrm{O}$ ciclo de aquecimento foi de $3^{\circ} \mathrm{C} /$ min com permanência de $3 \mathrm{~h}$ a $900^{\circ} \mathrm{C}$ ou $1100^{\circ} \mathrm{C}$. O ciclo de resfriamento foi de $4^{\circ} \mathrm{C} / \mathrm{min}$ até a temperatura ambiente.

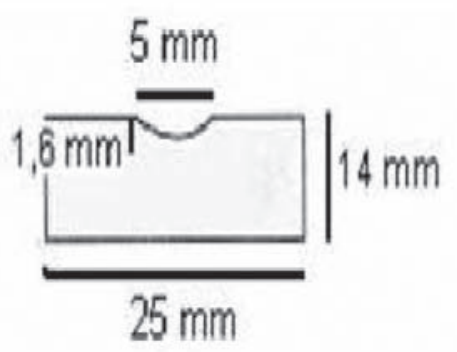

Figura 1. Dimensões da seção transversal do suporte cerâmico produzido.

Tabela 1. Composição e temperatura de sinterização dos corpos de prova cerâmicos.

\begin{tabular}{|c|c|c|c|c|c|c|}
\hline $\begin{array}{c}\text { Corpo de } \\
\text { Prova }\end{array}$ & $\begin{array}{c}\text { Mineral } \\
\text { Refratário }\end{array}$ & $\begin{array}{c}\text { Mineral } \\
\text { Refratário(\%) }\end{array}$ & Bentonita (\%) & $\begin{array}{c}\text { Silicato de } \\
\text { sódio (\%) }\end{array}$ & $\begin{array}{c}\text { Água } \\
(\%)\end{array}$ & $\begin{array}{c}\text { Temperatura de } \\
\text { sinterização ( }\end{array}$ \\
\hline C1 & Cordierita & 90 & - & 10 & 5 & 1100 \\
\hline C2 & Cordierita & 92 & - & 8 & 5 & 1100 \\
\hline C3 & Cordierita & 92 & 3 & 5 & 5 & 1100 \\
\hline C4 & Cordierita & 95 & 3 & 2 & 5 & 1100 \\
\hline C5 & Magnesita & 92 & - & 8 & 5 & 900 \\
\hline C6 & Magnesita & 92 & 5 & 3 & 5 & 1100 \\
\hline C7 & Magnesita & 95 & - & 5 & 5 & 900 \\
\hline C8 & Magnesita & 95 & - & 5 & 5 & 1100 \\
\hline C9 & Magnesita & 95 & 5 & - & 8 & 1100 \\
\hline C10 & Bauxita & 92 & 8 & - & 8 & 1100 \\
\hline C11 & Bauxita & 95 & - & 5 & 5 & 1100 \\
\hline C12 & Bauxita & 95 & 3 & 2 & 5 & 1100 \\
\hline C13 & Bauxita & 92 & 5 & 3 & 5 & 900 \\
\hline
\end{tabular}


Para a soldagem com os suportes cerâmicos produzidos foram utilizadas chapas de aço A-36 com dimensões de $100 \mathrm{X}$ $100 \times 6,4 \mathrm{~mm}$, chanfro em V com ângulo de $60^{\circ}$ e abertura de raiz de $2 \mathrm{~mm}$. Foi usado o processo de soldagem MIG-MAG com arame ER70S-6 de diâmetro 0,8 mm e gás de proteção com $75 \%$ Ar e $25 \% \mathrm{CO}_{2}$. Apenas o passe de raiz foi depositado, e foi avaliado por inspeção visual e macrografia.

Para a segunda etapa deste trabalho, novas formulações foram preparadas (tabela 2) usando apenas a cordierita como material refratário. Os experimentos de 1 a 4 avaliam o efeito da força de compactação e o tipo de aglomerante usado (bentonita e/ou silicato de sódio). Nos experimentos 5 a 8, apenas silicato de sódio foi usado como aglomerante. A proporção de água adicionada foi significativamente variada, de 8 a $32 \%$, com o objetivo de avaliar o processo de aglomeração. Ensaios de flexão em três pontos foram utilizados para avaliar a resistência da peça cerâmica, conforme ASTM C674-77 [7]. Foram feitos cinco ensaios para cada formulação da tabela 2 . A velocidade de aplicação da carga foi de $0,5 \mathrm{~mm} / \mathrm{min}$ e a distância entre os apoios foi de $90 \mathrm{~mm}$.

Foram realizadas as seguintes análises microestruturais: Difração de raios-X em difratômetro SHIMADZU XRD 7000, operando com radiação de Cobre $(\mathrm{Cu})$ e 2 variando de 10 a $50^{\circ}$. A microestrutura do suporte cerâmico foi analisada por microscopia eletrônica de varredura (MEV) no equipamento SHIMADZU SSX-550. A microscopia ótica (MO) foi realizada em estéreo-microscópio com câmara fotográfica adaptada.

O ensaio de absorção de água foi realizado conforme ASTM C372-72 [8]. Após os suportes serem submetidos ao ensaio de ruptura de três pontos, foram secos em estufa a $110^{\circ} \mathrm{C}$ durante 24 horas, resfriados em dissecador e pesados. Em seguida foram colocados em recipientes com água destilada e mantidos em água fervente por 2 horas, resfriados submersos em água até a temperatura ambiente. Em seguida retirou-se a água superficial de cada peça, registrando-se a massa. A absorção de água (AA) foi calculada de acordo com a seguinte expressão:

$A A(\%)=\frac{(P u-P s)}{P s} \times 100$

Onde Pu e Ps são as massas (g) das peças saturadas em água (úmidas) e secas, respectivamente.

Para as formulações da tabela 2 também foi realizada a soldagem do passe de raiz, conforme já indicado anteriormente para as formulações da tabela 1 .

\section{Resultados e Discussão}

A primeira etapa deste trabalho teve por objetivo avaliar o processo de fabricação do suporte cerâmico e formulações com as matérias-primas identificadas como de uso potencial. Em relação às etapas do processo de fabricação, pode-se afirmar que estas foram consideradas satisfatórias, com aspecto mostrado na figura 2. Ressalta-se que as etapas aqui propostas são coincidentes com o processo de fabricação convencional de peças cerâmicas.

Na tabela 3 pode ser observado que o comprimento e a largura dos suportes cerâmicos não sofreram alteração, devido a dimensão padrão do molde utilizado na compactação. Já em relação à espessura dos corpos de prova, pode ser observada uma diferença significativa na tabela 3 . Esta diferença na espessura foi atribuída à densidade das matérias-primas usadas. De fato, a cordierita apresenta menor densidade $\left(1,90 \mathrm{~g} / \mathrm{cm}^{3}\right)$ em relação à magnesita $\left(2,9 \mathrm{~g} / \mathrm{cm}^{3}\right)$ e a bauxita $\left(2,38 \mathrm{~g} / \mathrm{cm}^{3}\right)$, justificando a maior espessura obtida no suporte cerâmico produzido com cordierita. Para se obter uma mesma espessura deveria ter sido calibrado a massa em função da densidade da matéria-prima.

Tabela 2. Formulações e forças de compactação dos corpos de prova para ensaio de flexão. Todas foram sinterizadas a $1100{ }^{\circ} \mathrm{C}$.

\begin{tabular}{|c|c|c|c|c|c|}
\hline Formulação & $\begin{array}{c}\text { Cordierita } \\
\text { (\%peso) }\end{array}$ & $\begin{array}{c}\text { Bentonita } \\
\text { (\%peso) }\end{array}$ & $\begin{array}{c}\text { Silicato de } \\
\text { Sódio (\%peso) }\end{array}$ & Água (\%) & $\begin{array}{c}\text { Força de } \\
\text { compactação (ton) }\end{array}$ \\
\hline 1 & 92 & - & 8 & 5 & 7 \\
\hline 2 & 92 & - & 8 & 5 & 15 \\
\hline 3 & 92 & 5 & 3 & 5 & 7 \\
\hline 4 & 92 & 5 & 3 & 5 & 15 \\
\hline 5 & 90 & - & 10 & 10 & 7 \\
\hline 6 & 90 & - & 10 & 20 & 7 \\
\hline 7 & 92 & - & 8 & 8 & 7 \\
\hline 8 & 92 & - & 8 & 32 & 7 \\
\hline
\end{tabular}

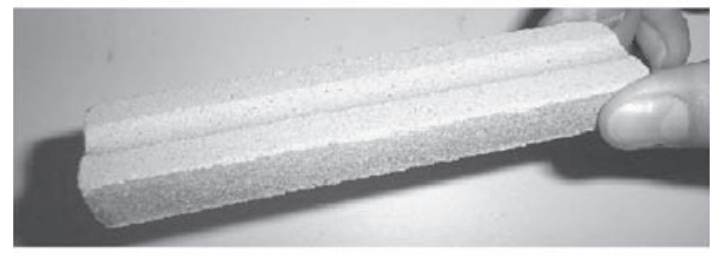

(a)

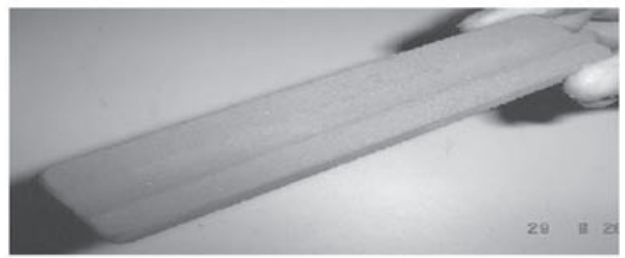

(b)

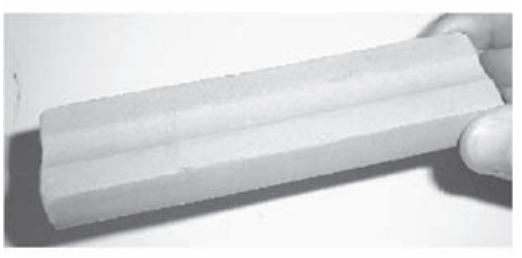

(c)

Figura 2. Suporte de Cordierita (a), Magnesita (b) e Bauxita (c). 
Tabela 3. Dimensões dos supores cerâmicos produzidos.

\begin{tabular}{|c|c|c|c|}
\hline Tipo de suporte & Comprimento $(\mathrm{mm})$ & Largura $(\mathrm{mm})$ & Espessura $(\mathrm{mm})$ \\
\hline Cordierita & 114,28 & 25,42 & 14,23 \\
\hline Magnesita & 114,92 & 25,35 & 10,37 \\
\hline Bauxita & 114,20 & 25,35 & 9,10 \\
\hline
\end{tabular}

Em relação à temperatura de sinterização, alguns suportes cerâmicos de cordierita e bauxita sinterizados a $900{ }^{\circ} \mathrm{C}$ ficaram frágeis e fraturaram-se por si só após a sinterização. Apenas os de magnesita apresentaram boa qualidade após a sinterização a $900{ }^{\circ} \mathrm{C}$, no qual foi realizada a soldagem. Por outro lado, todos os suportes sinterizados a $1100^{\circ} \mathrm{C}$ não apresentaram fragilidade. A fragilidade ao manuseio observada em alguns suportes é uma indicação que a sinterização deve ser realizada em temperatura não inferior a $1100^{\circ} \mathrm{C}$.

A figura 3 mostra o aspecto do cordão de solda e do suporte cerâmico após a soldagem. Observa-se que o suporte cerâmico de cordierita (figura 3a) permaneceu intacto, suportando as elevadas temperaturas resultantes do contato com o metal líquido. $\mathrm{O}$ aspecto e o acabamento do cordão de solda foram considerados como adequados pela inspeção visual, não tendo sido observadas descontinuidades como inclusões, trincas, poros e mordeduras ao longo do cordão de solda. Também não foi observada a adesão de material cerâmico no cordão de solda. $\mathrm{O}$ suporte cerâmico de bauxita não suportou a temperatura elevada do metal de solda líquido durante a soldagem, sendo observada a sua fragmentação assim como alguma adesão de material cerâmico no cordão de solda (figura $3 b$ ). $\mathrm{O}$ aspecto do cordão não foi considerado adequado pela inspeção visual. $\mathrm{O}$ suporte cerâmico de magnesita também não suportou a temperatura elevada do metal de solda líquido durante a soldagem, sendo observada sua total fragmentação após a soldagem, não sendo possível incluí-lo na figura 3c. Porém, não foi observada a adesão de material cerâmico no cordão de solda e a inspeção visual considerou como adequado o aspecto do cordão.

Os resultados apresentados na figura 3 mostram que as três matérias-primas (cordierita, bauxita e magnesita) possuem bom potencial para serem usadas na fabricação de suportes cerâmicos para soldagem.

A figura 4 apresenta macrografias da seção transversal dos cordões de solda obtidos com os suportes cerâmicos produzidos de cordierita, bauxita e magnesita. Observa-se que houve penetração nas laterais do chanfro e reforço de solda apropriado na raiz. Não foram observadas descontinuidades.

Os resultados dos testes de soldagem obtidos com as formulações do suporte de solda utilizando a cordierita foram considerados os mais adequados, produzindo um cordão de solda com formato e acabamento satisfatórios e isento de defeitos. Em relação às formulações com magnesita e bauxita, alguns aperfeiçoamentos ainda devem ser feitos em sua formulação ou técnica de fabricação, como, por exemplo, aumentar a temperatura de sinterização, aumentar a quantidade de água à massa cerâmica, aumentar o tamanho de grão da matéria-prima ou aumentar a pressão de compactação.

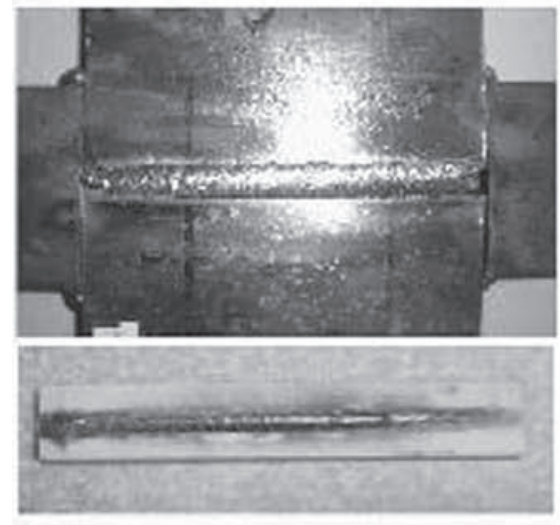

(a)

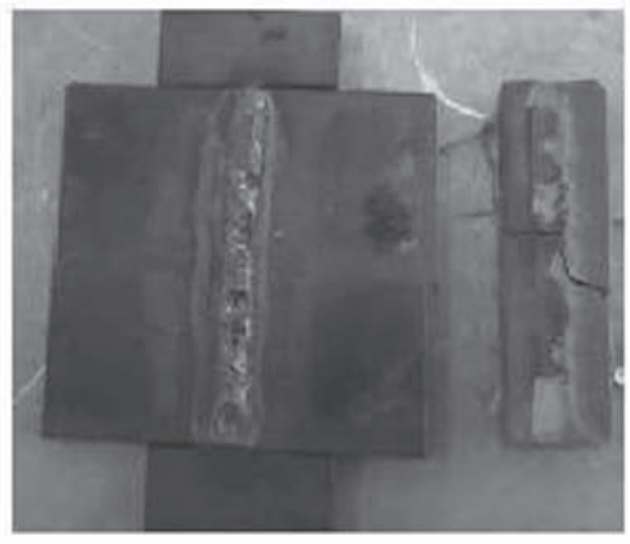

(b)

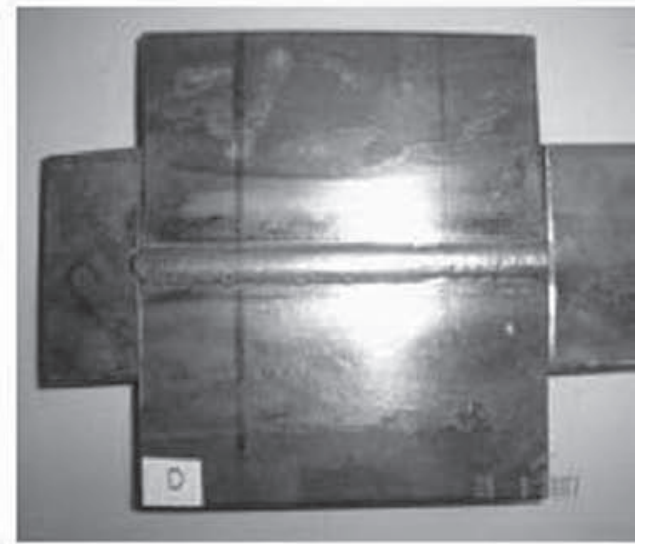

(c)

Figura 3. Após a soldagem, (a) Corpo de prova C1 com a Cordierita, (b) Corpo de prova C10 com a Bauxita e (c) corpo de prova C5 com Magnesita.

$\mathrm{Na}$ segunda etapa do trabalho, apenas formulações com cordierita foram usadas (tabela 2). Todas apresentaram boa resistência ao manuseio, sem quebras ou lascas após sinterização.

A figura 5 apresenta a resistência à flexão dos suportes de solda. As seguintes observações podem ser feitas: i) o aumento da pressão de compactação aumenta a resistência a flexão, que pode ser verificado ao compara os experimentos 1 com 2 e 3 com 4; ii) o uso de apenas silicato de sódio como aglomerante aumenta a resistência à flexão em relação aos que contêm bentonita, que pode ser verificado ao comparar os experimentos 1 com 3 e 2 com 4; iii) o efeito da adição de água não foi conclusivo, e pode 
ser observado comparando-se os experimentos 5 a 8 . Nestes, observa-se que melhor resistência a flexão foi obtida com 8 e $32 \%$ de água (corpos de prova 7 e 8 ) que com 10 e $20 \%$ de água (corpos de prova 5 e 6). Era esperado que com uma maior concentração de água houvesse uma melhor distribuição de moléculas de silicato de sódio na água e melhor distribuição na massa cerâmica, melhorando a resistência a flexão, o que de fato não ocorreu. Uma causa possível para justificar os baixos valores de resistência a flexão é que os corpos de prova encontravam-se previamente trincados, fato que não pode ser verificado.

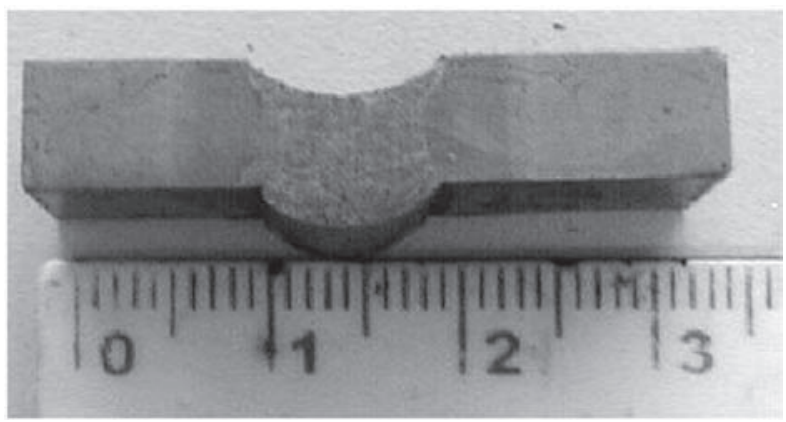

(a)

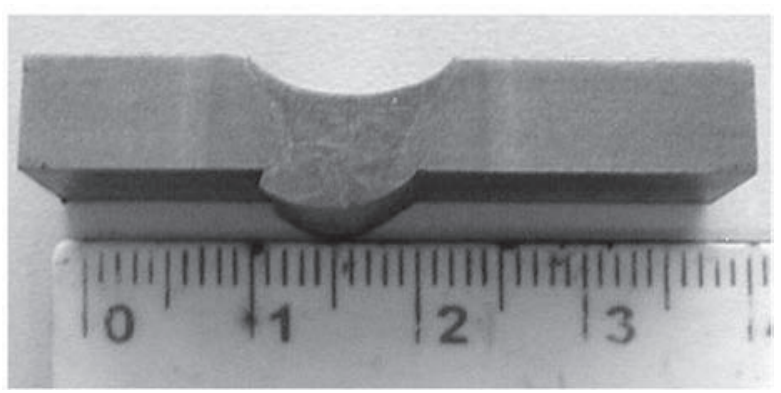

(b)

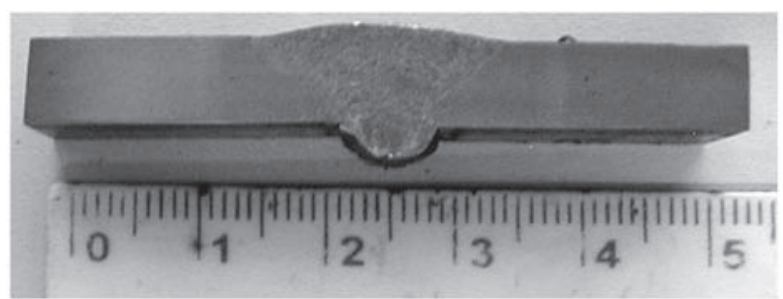

(c)

Figura 4. Macrografias da seção transversal do cordão de solda com os corpos de prova $\mathrm{C} 2$ de cordierita (a), corpo de prova $\mathrm{C} 4$ de magnesita (b) e corpo de prova $\mathrm{C} 10$ de bauxita.

A figura 6 apresenta os difratogramas de queima das composições 5, 6, 7 e 8 . Pode-se observar que todas as composições apresentam composição mineralógica similares constituída de cordierita, mulita, quartzo e espinélio.

A figura 7 mostra as micrografias obtidas por MEV da superfície dos suportes cerâmicos produzidos com as composições avaliadas. É possível observar que todas as composições dos suportes cerâmicos apresentam uma superfície pouco compacta, uma textura rugosa e com muita porosidade. Estas características estão associadas, sobretudo, à baixa temperatura de queima empregada, $1100^{\circ} \mathrm{C}$. Um aumento da pressão de compactação juntamente com incremento da temperatura de queima poderiam contribuir para uma significativa redução da porosidade das cerâmicas produzidas.

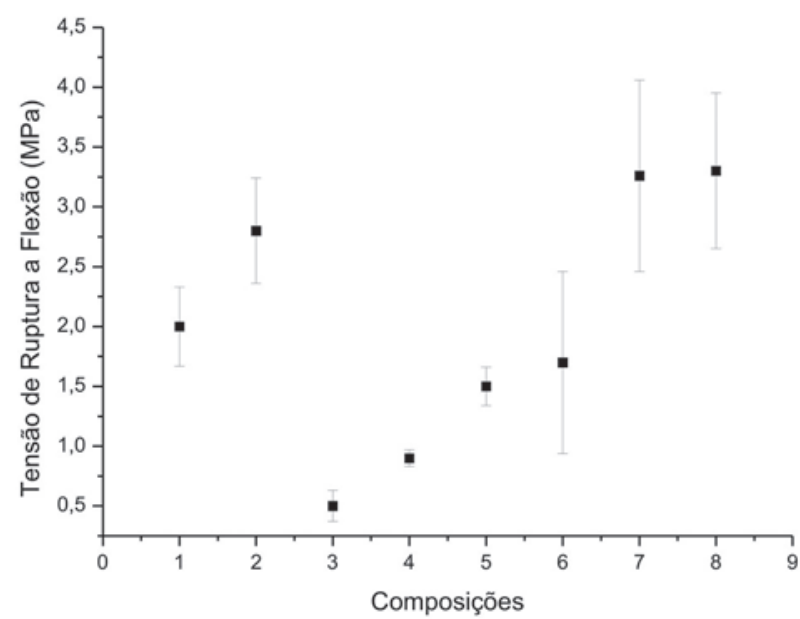

Figura 5. Tensão de ruptura à flexão dos suportes cerâmicos produzidos referente a tabela 2 .

A figura 8(a) mostra outra micrografia do suporte cerâmico produzido com a composição 8 , onde os pontos indicados foram submetidos a mapeamento por EDS. É possível verificar a presença significativa de alumínio, silício e magnésio, figuras 8 (b) e (d), elementos constituintes no mineral cordierita. Na figura 8(c) os elementos encontrados devem estar associados com a presença de mulita. As fases observadas são cordierita e mulita como mostra o difratograma de raios- $X$ após a queima do suporte cerâmico produzido com a composição 8 , figura 6(d). O fato de não terem sido encontradas as outras fases detectadas no difratograma de raios-x (quartzo e espinélio) foi atribuído ao fato da análise por EDS ter sido realizada em apenas três pontos.

A seguir são apresentadas micrografias, figura 9, obtidas por MO da superfície das cerâmicas após a queima. Nota-se que as partículas de quartzo, indicados pelo elipse, estão relativamente bem distribuídas na matriz de cordierita. Nota-se ainda poros, indicados por quadrado, e falhas, setas, em todas as regiões das cerâmicas. Estes defeitos estão associados aos parâmetros de processamento utilizados, conforme já discutido.

A Figura 10 apresenta a absorção de água das composições $5,6,7$ e 8 . Nota-se que ocorre uma certa variação desta propriedade que ocorre na faixa de 20,64 a 25,03\%. Embora a melhor composição tenha sido a 6 , os valores obtidos são relativamente elevados e devem acarretar baixa resistência mecânica.

$\mathrm{Na}$ figura 11 pode-se observar que os suportes resistiram o elevado aporte de calor durante a soldagem. Os suportes fundiram-se localmente e foram efetivos em proteger o metal de solda líquido. As macrografias e a inspeção visual na parte inferior do cordão de solda (raiz da solda) que esteve em contato com o suporte cerâmico produzido, apresentaram excelentes acabamentos, sendo assim, não foi observado descontinuidades como inclusões, trincas, poros e mordeduras. 


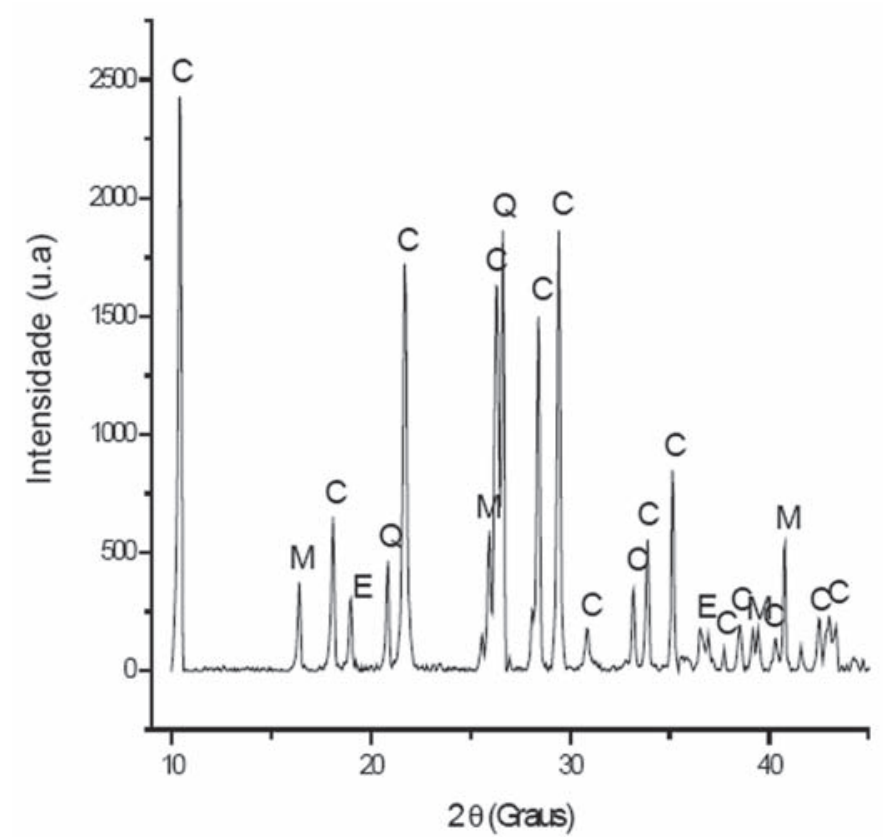

(a)

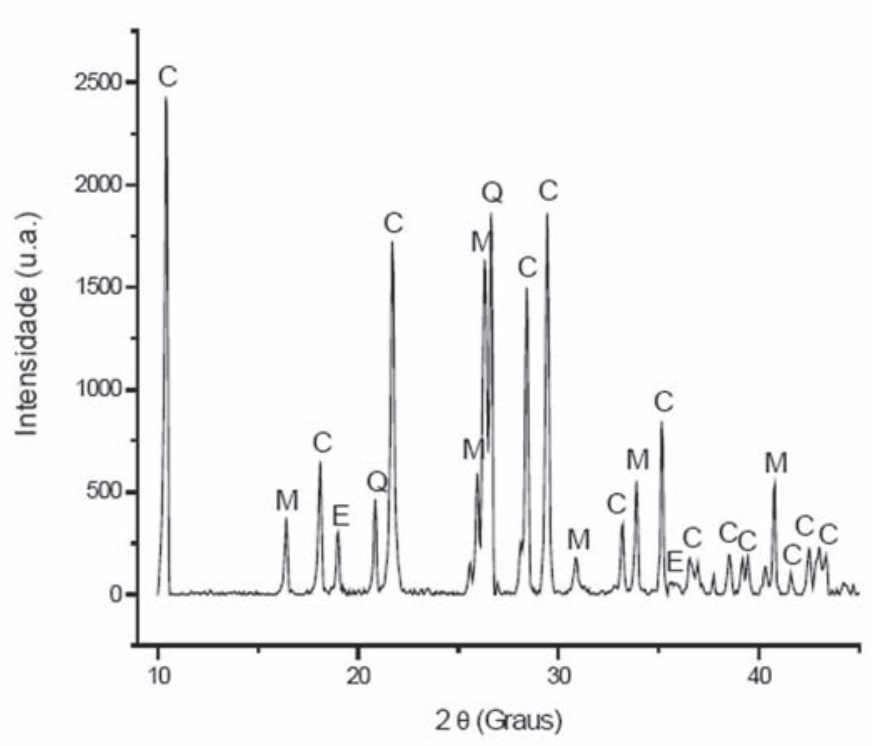

(c)

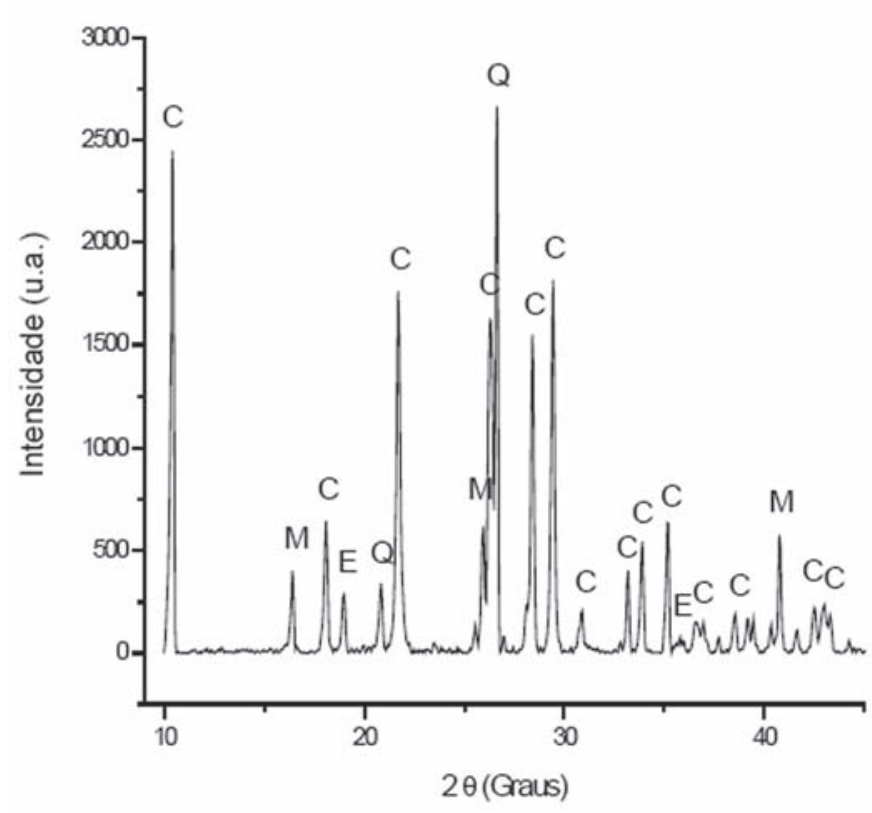

(b)

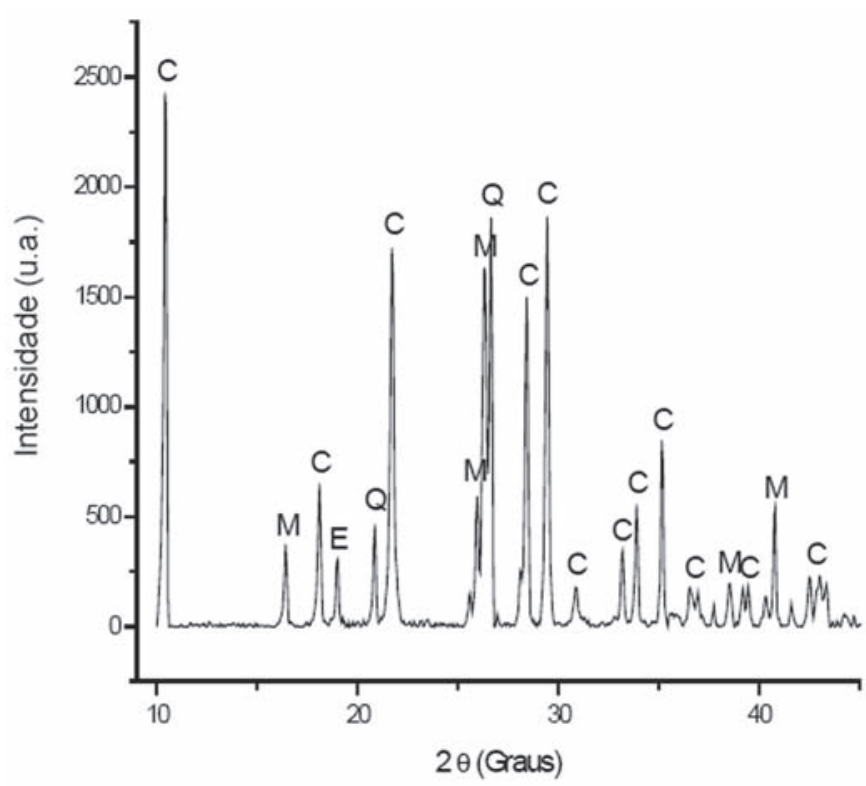

(d)

Figura 6. Difratogramas de raios-X das composições após a queima. (a) 5, (b) 6, (c) 7 e (d) 8 (C=cordierita, M=mulita, Q= quartzo e $\mathrm{E}=$ espinélio). 


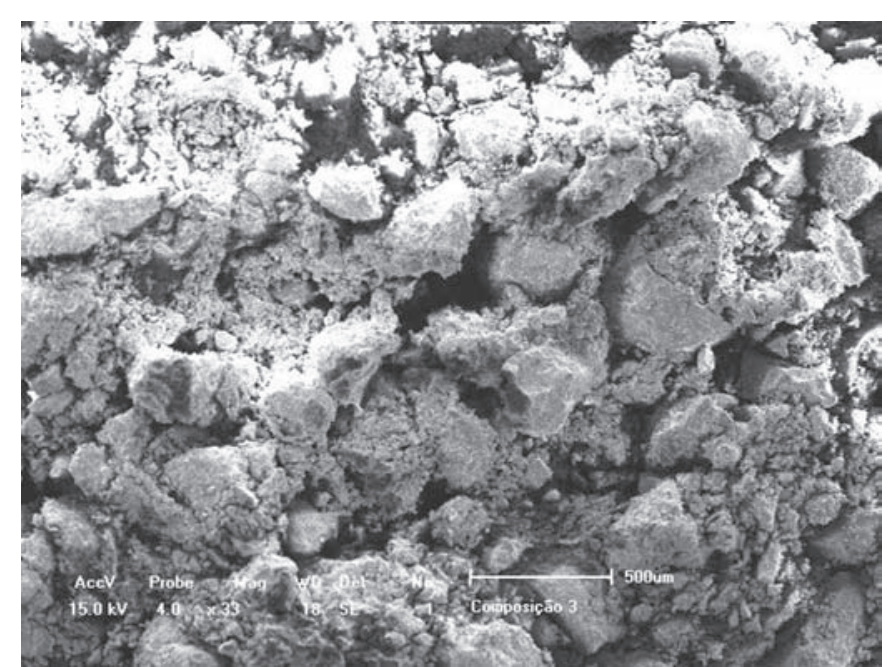

(a)

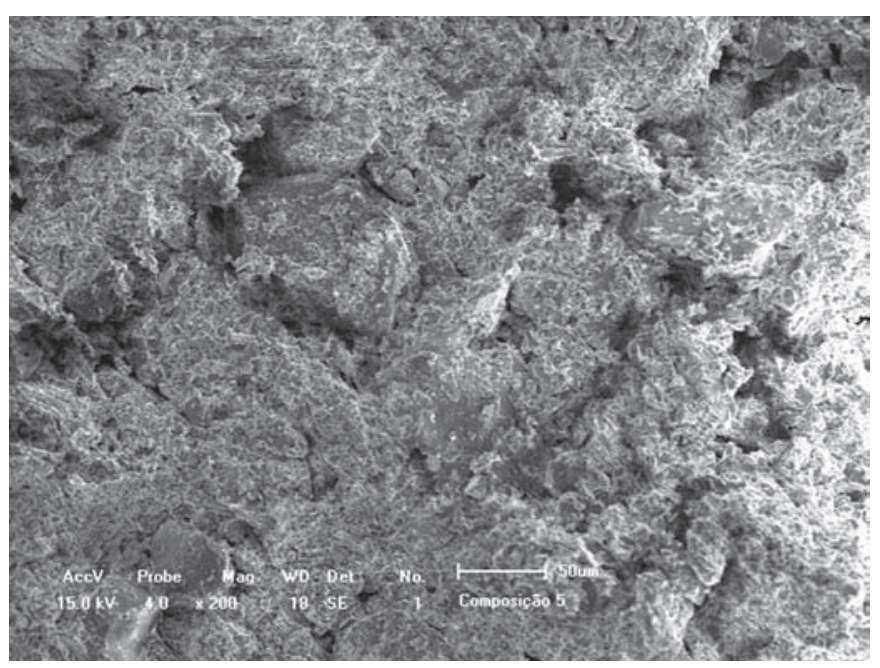

(c)

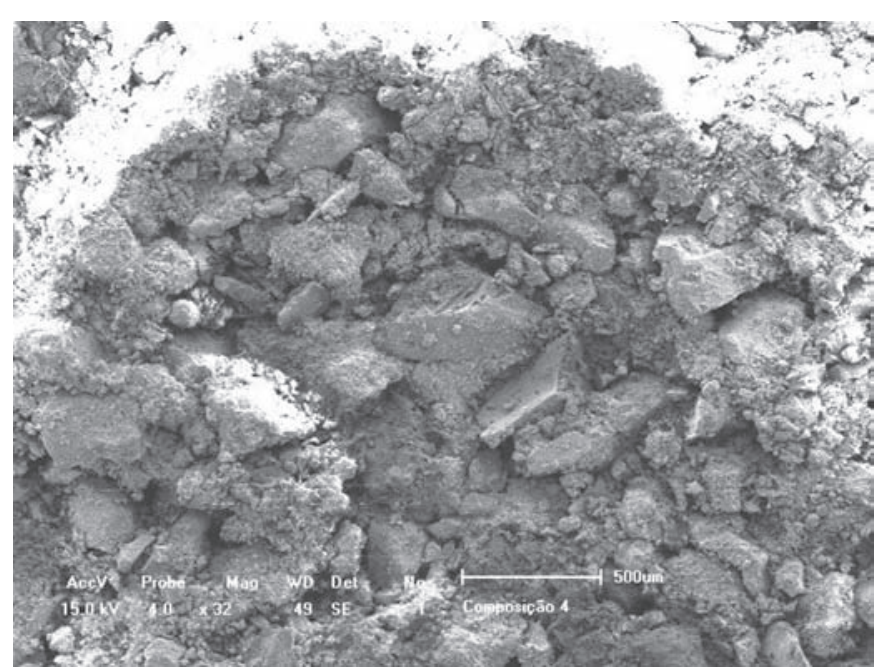

(b)

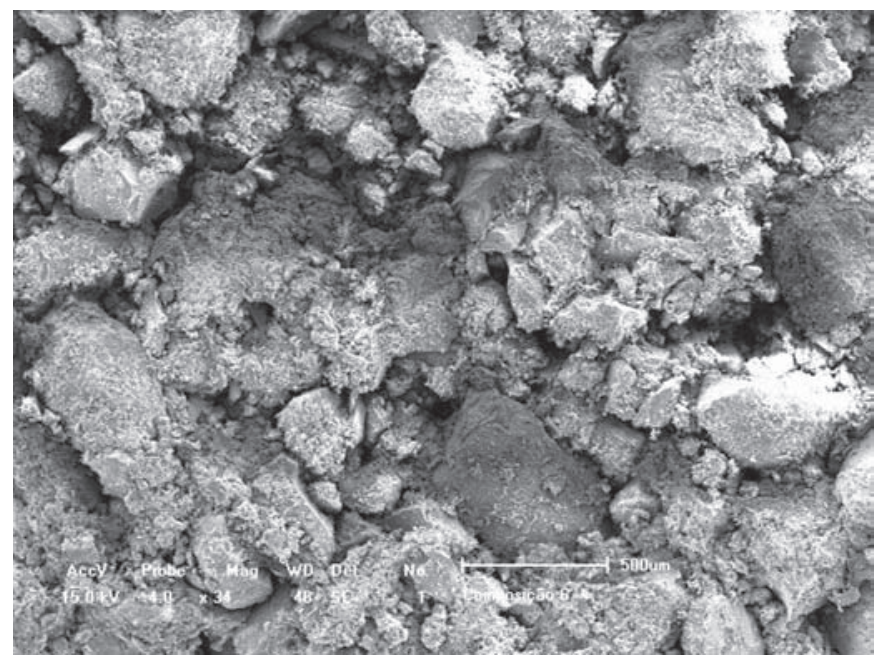

(d)

Figura 7. Micrografia de MEV da superfície lisa do suporte cerâmico produzido com as composições (a) 5, (b) 6, (c) 7 e (d) 8.

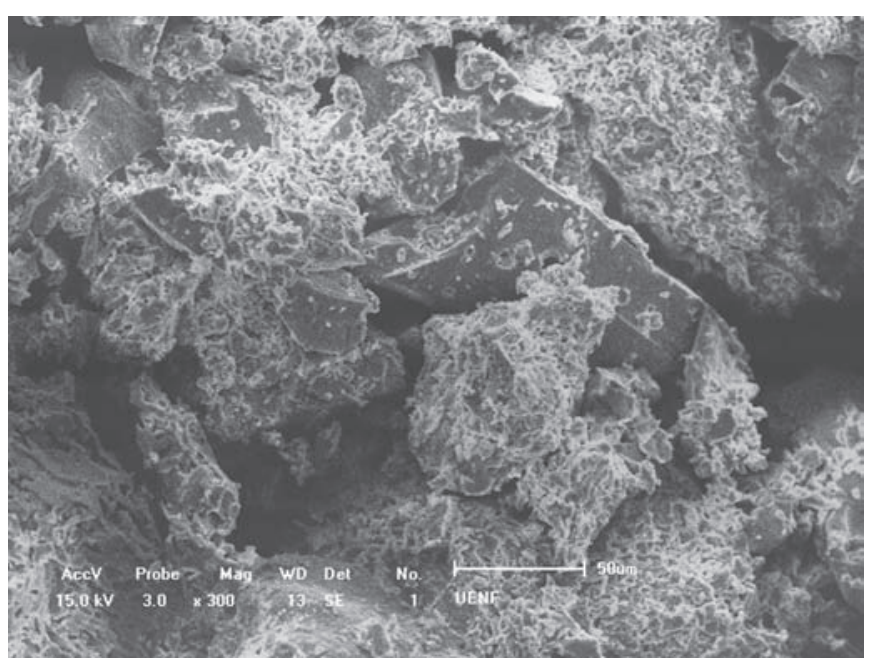

(a)

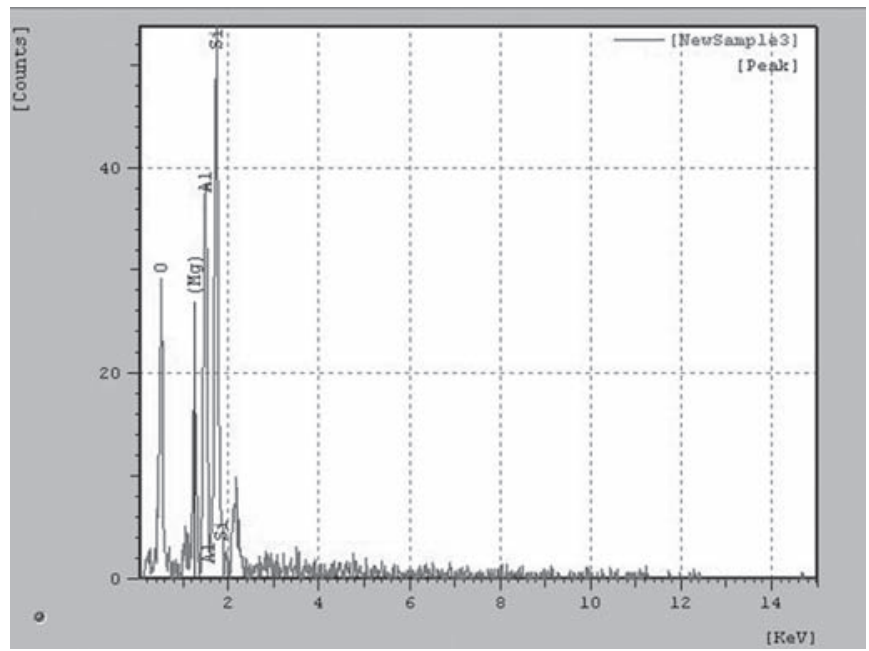

(b) 


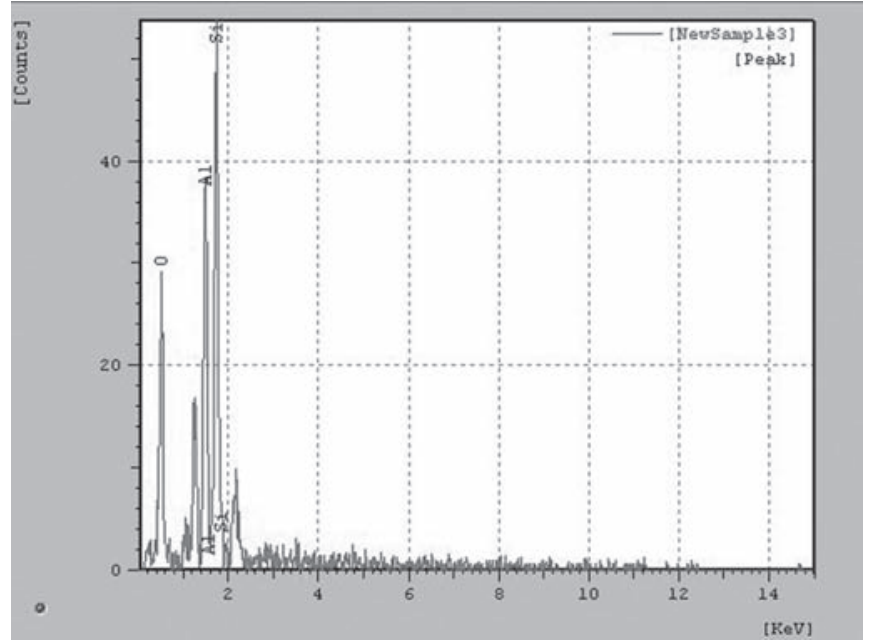

(c)

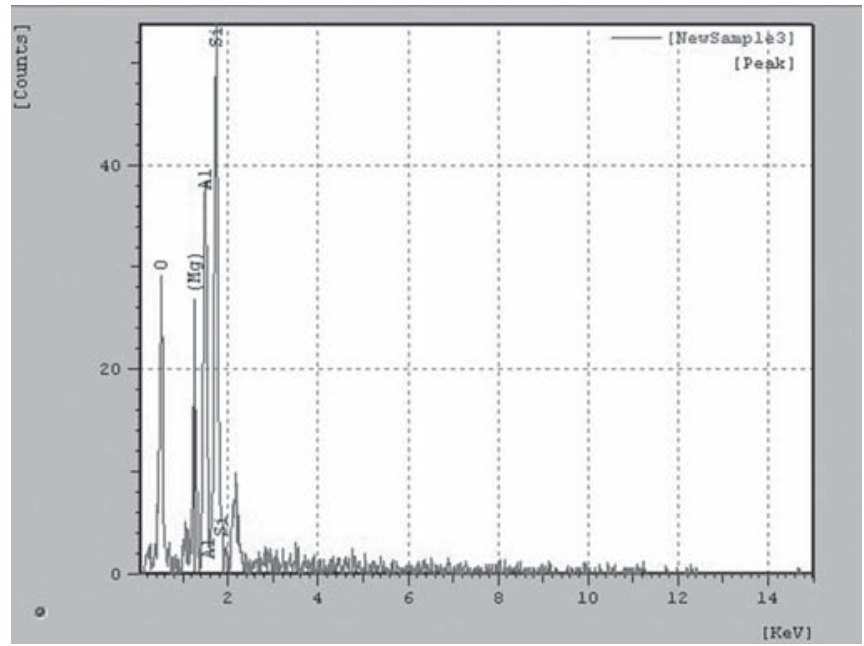

(d)

Figura 8. Micrografia da superfície do suporte cerâmico produzido com a composição 8. (a) aumento de 300X e EDS pontual do ponto $1(\mathrm{~b})$, ponto 2 (c) e ponto $3(\mathrm{~d})$.

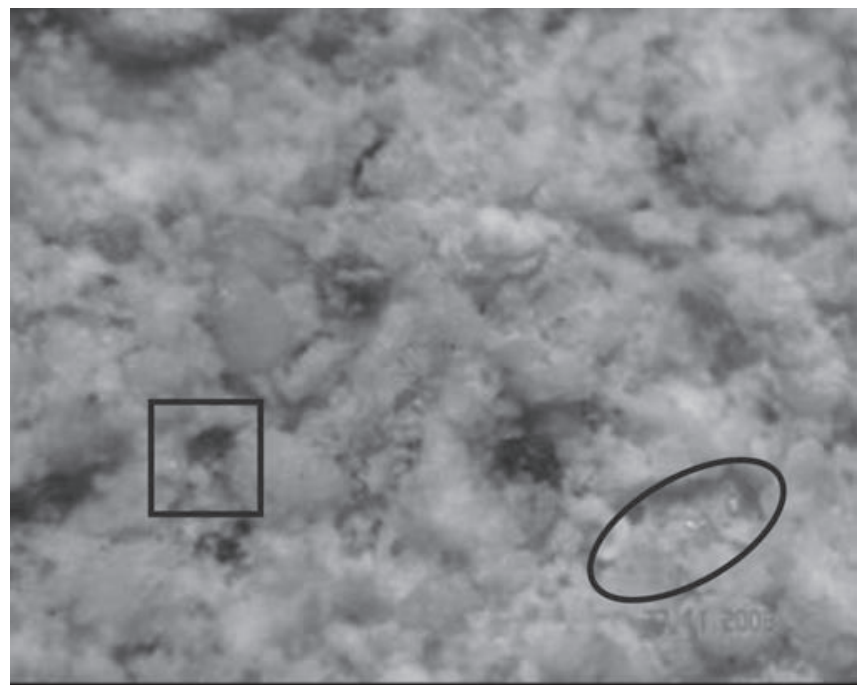

(a)

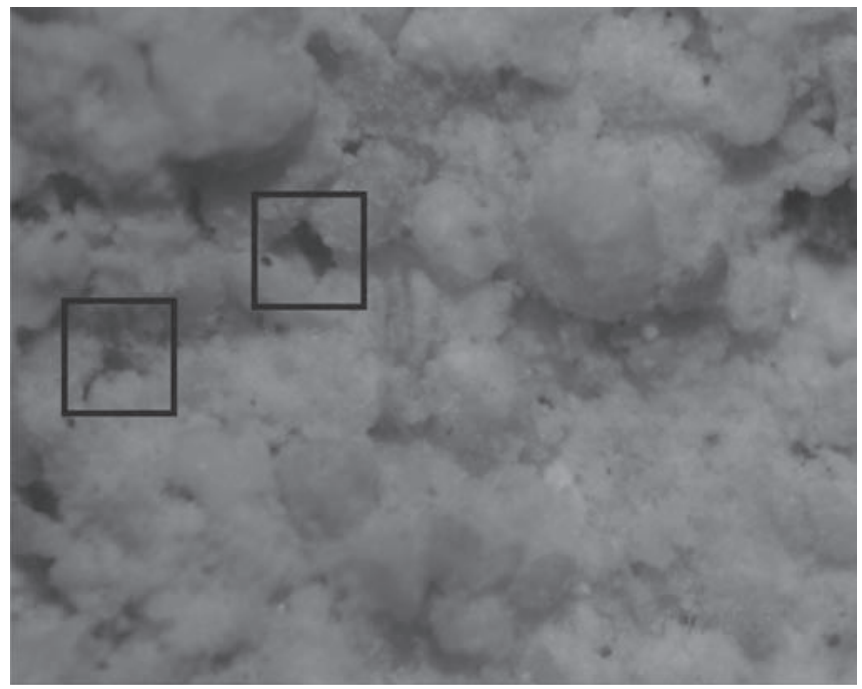

(c)

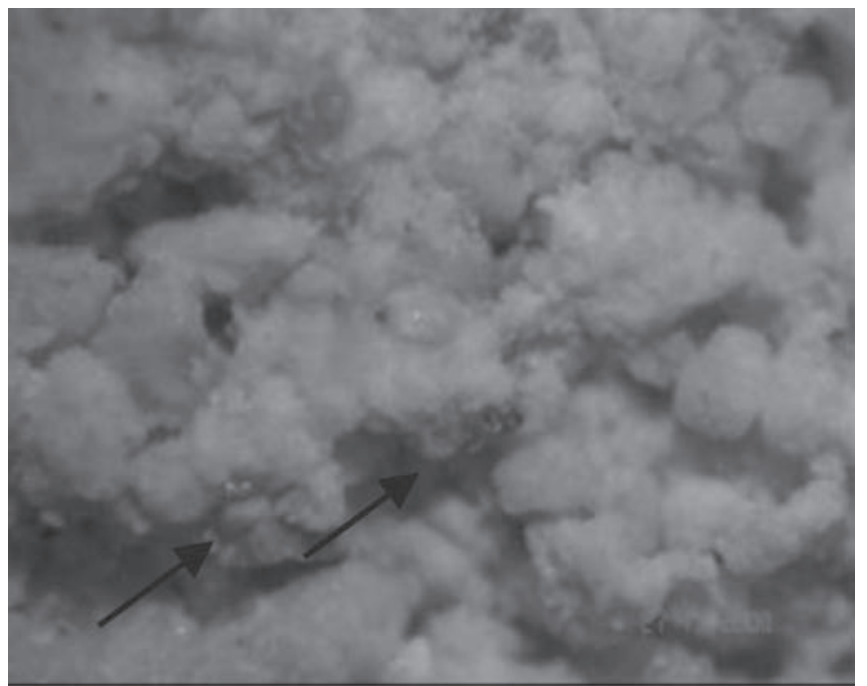

(b)

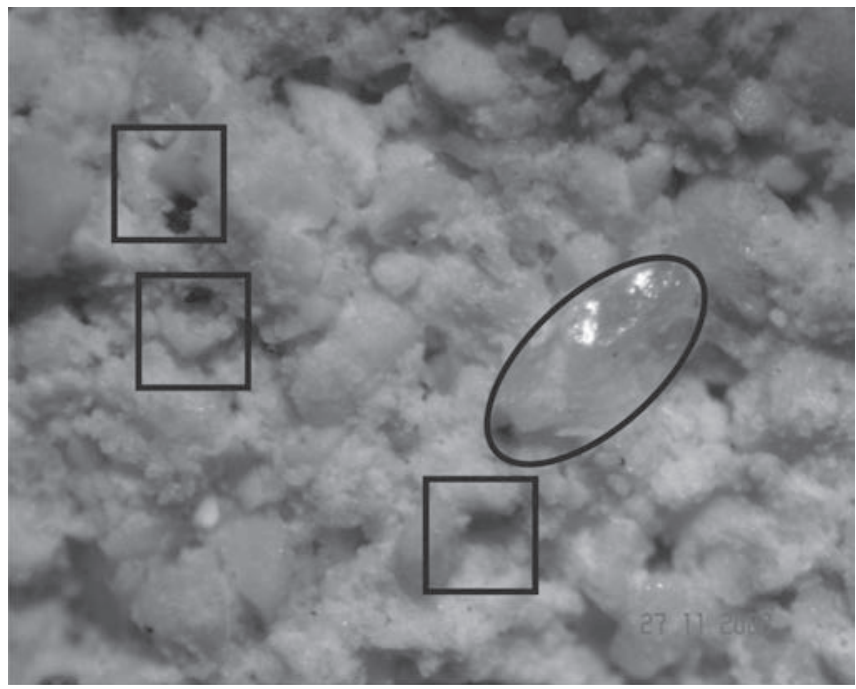

(d)

Figura 9. Micrografia obtida por MO dos suportes cerâmicos produzidos com as com as composições: 5(a); 6(b), 7(c) e 8(d). 


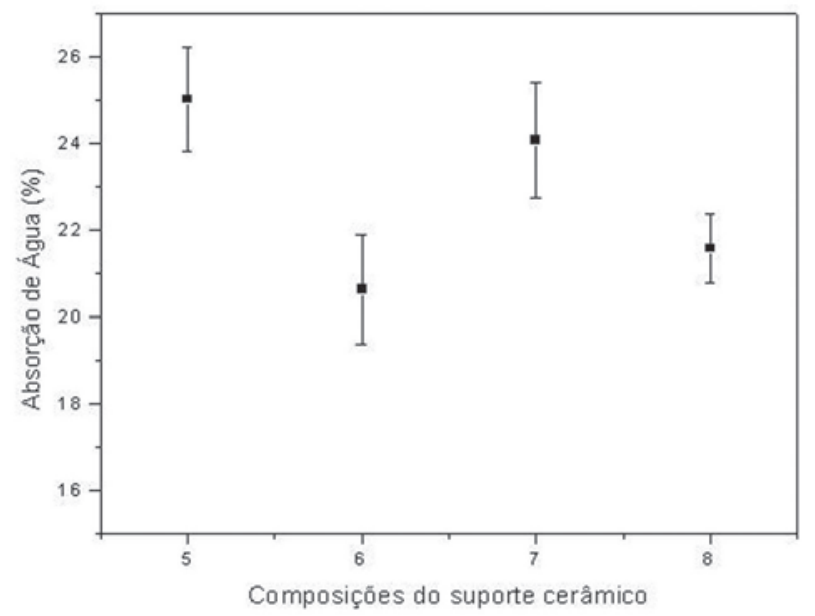

Figura 10. Absorção de água dos suportes cerâmicos produzidos.

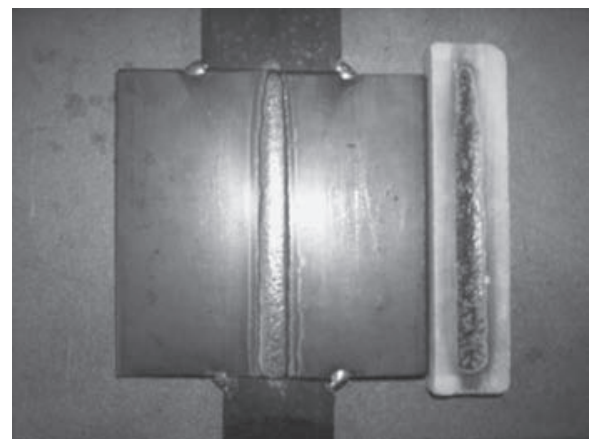

(a)

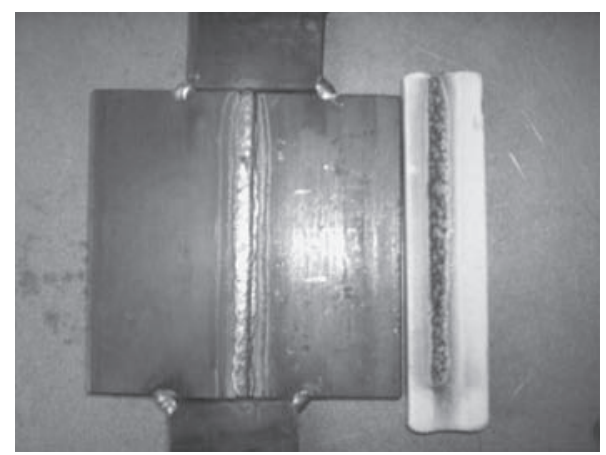

(c)

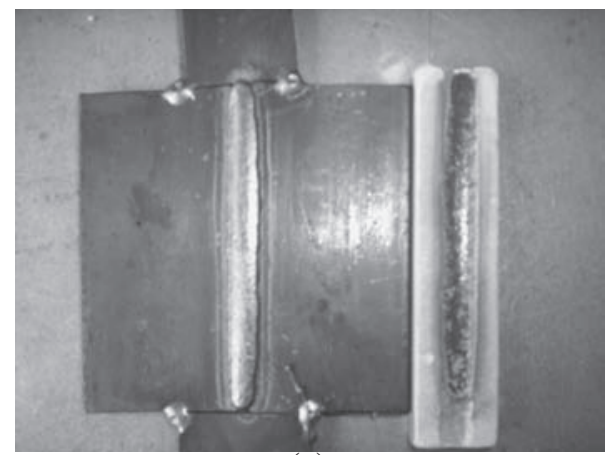

(e)

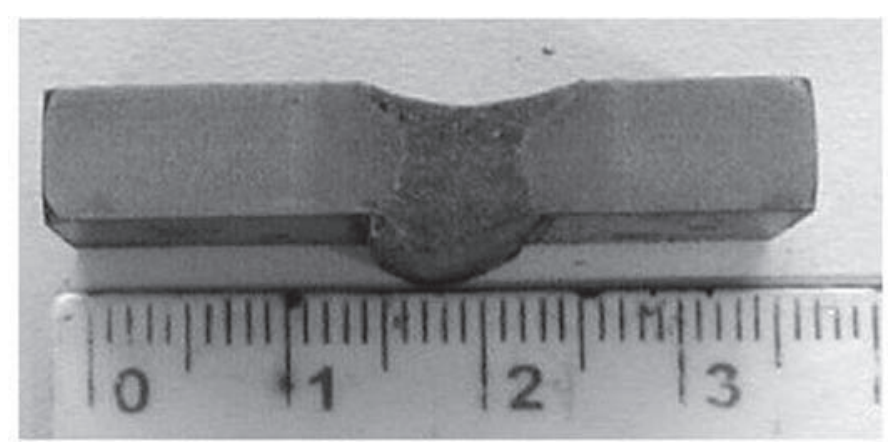

(b)

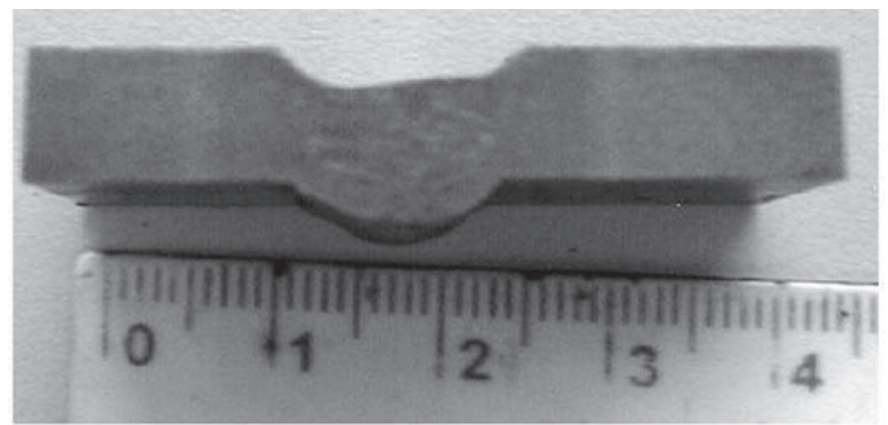

(d)

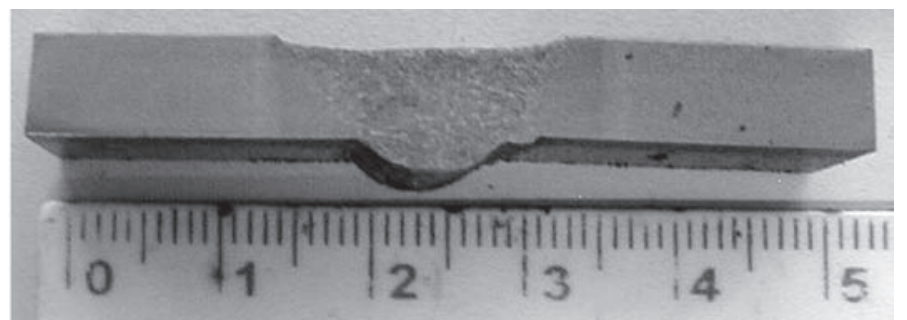

(f)

Figura 11. Soldagem com os corpos de prova produzidos e macrografias dos cordões de solda obtido com as composições: 6(a, b), 7(c, d) e $8(e, f)$. 


\section{Conclusões}

No trabalho realizado, estudando-se formulações, matériasprimas, técnica de fabricação de suporte de solda cerâmico e a sua aplicação no passe de raiz, as seguintes conclusões foram obtidas:

Entre as matérias primas testadas, o suporte cerâmico formulado com cordierita foi considerado o que apresentou melhor comportamento durante o manuseio e após a soldagem.

$O$ processo de fabricação convencional de cerâmica mostrou-se adequado para a obtenção de suporte para soldagem unilateral.

Foi constatado que quando sinterizados a $900{ }^{\circ} \mathrm{C}$, o suporte apresentava-se muito quebradiço, não estando em boas condições para a realização da soldagem, determinando-se assim, a temperatura mínima de $1100{ }^{\circ} \mathrm{C}$ para a sinterização do suporte cerâmico.

O aumento da força de compactação e o uso de apenas silicato de sódio como aglomerante proporcionaram um aumento na resistência a flexão do suporte cerâmico. $\mathrm{O}$ efeito da adição de água mostrou-se não conclusivo.

\section{Agradeçimentos}

À FAPERJ e ao CNPq pelo apoio financeiro, por meio de bolsas de estudo e projetos financiados.

\section{Referências}

[1] PARANHOS, R. P. R., SOUZA, A. C Soldagem a Arco Submerso. Rio de Janeiro: FIRJAN/SENAI, 87 p., 1999.

[2] MALIN, V. "Root Weld Formation in Modified Refractory Flux One-Sided Welding: part 1 - Effect of Welding Variables, Welding journal, vol. 80 pp. 217s- 226s, e part 2 - Effect of Joint Geometry, Welding journal, vol. 80 pp. $227 \mathrm{~s}-237 \mathrm{~s}$, September 2001.

[3] ALMEIDA, L.L.P. Desenvolvimento de suporte cerâmico para aplicação em soldas unilaterais com elevada produtividade. 2009, 111p. Tese ( Mestrado em Engenharia e Ciência dos Materiais) - Universidade Estadual do Norte Fluminense, UENF, Campos dos Goytacazes, Rio de Janeiro.

[4] CALLISTER JR., W. D. Ciência e Engenharia de Materiais. $5^{\text {a }}$ ed. Rio de Janeiro: LTC, 589 p, 2002.

[5] VAN VLACK, L.H. Princípios de Ciência e tecnologia dos materiais. 4 ed. Rio de Janeiro: Campus, 566p, 1984.

[6] ANDRADE, S. T, Mapeamento do processo mecanizado de Soldagem unilateral fcaw com backing Cerâmico aplicável no passe de raiz em aço Carbono. 2007, 103p. Belo Horizonte MG, Universidade Federal de Minas Gerais - UFMG.

[7] ASTM C674-77. American Society for Testing And Materials. Flexural properties of ceramic whiteware Materials. 1977.

[8] ASTM C373-72. American Society For Testing And Materials. Test method for water absorption, bulk density, apparent porosity and apparent specific gravity of fired whiteware products. 1977. 